\title{
Flood Risk Mapping for Emergency Management by Applying Grid-based Model
}

\author{
Kun Yeun Han ${ }^{1,1}$, Jun Hyung Park ${ }^{2}$, and Hehun Choi $^{3}$ \\ ${ }^{1}$ Department of Civil Engineering, Kyungpook National University, Daegu, Korea \\ ${ }^{2}$ National Civil Defense and Disaster Management Training Institute, Chonan, Korea \\ ${ }^{3}$ Ministry of Interior and Safety, Sejong, Korea
}

\begin{abstract}
A grid-based numerical model is developed by improving the diffusion hydrodynamic model that can accurately reflect LiDAR data and enable an efficient hydraulic analysis by linking river and drainage networks. In order to verify 2D model, recent flood events, which occurred in the Gimcheon area during Typhoon Rusa on 2002 is considered. For the estimations of flood disaster vulnerability index, population density, household income, access to evacuation route/time, and shelter information are included. The flood hazard map considering flood depth, velocity, flood arrival time is combined with the flood vulnerability information to derive a flood risk map. The flood risk map presented in this study can provide useful information for the preparation of evacuation plan through accurate flood hazard results and disaster vulnerability index.
\end{abstract}

\section{Introduction}

In recent years, the frequent flooding due to torrential rains that have concentrated in urban areas, and the damage to property and human lives has become very serious. The major cities in Korea suffered from flood damage due to typhoons and heavy rainfall since 2000. Various measures including structural and nonstructural methods have been prepared to mitigate flood disaster. Preparation of flood hazard and disaster information maps by local government is very important, however, the detail contents presented in these maps seem to be insufficient for an efficient evacuation/recovery plan. In this paper, grid based twodimensional flood analysis model that can reflect various conditions such as LiDAR data, grid size, and building/street conditions are applied by supplementing the disadvantages of existing numerical model to derive accurate risk for disaster. Based on the validated gridbased model, flood hazard map can be developed for the future situations and provided accurate hydraulic analysis results for making the disaster plan. The flood risk maps are presented by combining flood hazard with flood vulnerability, which consider various social and human factors.

\footnotetext{
${ }^{1}$ Corresponding author: kshanj@knu.ac.kr
} 


\section{Application of Grid-based Model}

In this study, a new grid-based model is developed by improving the diffusion hydrodynamic model that can accurately reflect topographic data and enable an efficient hydraulic analysis through linkage with and extension of other models. Sub-Grid technique is extended to shorten simulation time and maintain accuracy. A real-time, two-dimensional inundation model is established to overcome the disadvantage of long computational time in the existing 2D flood model. Real-time inundation analysis can be an important factor in determining the inundated area and the inundation depth. Accurate flood analysis results entail the construction of precise topographic data including LiDAR data and the analysis of flooding from a dense compute grid, making it difficult for a real-time flood analysis.

The model is verified by applying to the urban flood occurred in Gimcheon city during typhoon Rusa on 2002. Most of the watersheds including the apartment complexes and residential areas are lower than higher water surface elevation of the adjacent river. ArcGIS is used to extract contours, convert to TIN, and produce a DEM with 3-meter resolution.

SWMM model is applied to calculate the amount of overflow that occurred in excess of the stormwater and sewer pipe capacity. A total of 43 subwatersheds and 44 main pipelines are constructed and rainfall input data are applied at a Gimcheon station from August 30 to September 1, 2002. The downstream boundary condition was applied to the observed water level during Typhoon Rusa.

The rainfall data, the boundary conditions at the outlet, location of overflowed manhole and overflow rates are shown in Fig. 1, respectively. The overflows from six manholes as a result of 1D drainage analysis are estimated. The estimated manhole overflows are applied as a source term for $2 \mathrm{D}$ analysis with a $3 \mathrm{~m}$ resolution DEM. Comparisons of actual surveyed inundated areas with the simulated as shown in Fig. 2, which result in a suitability of $81.1 \%$.

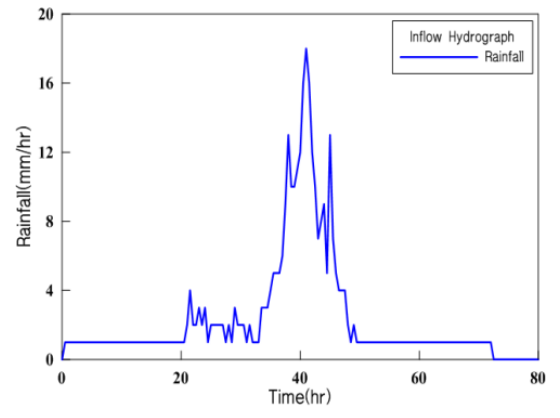

(a) Time Series of Rainfall(Gimcheon)

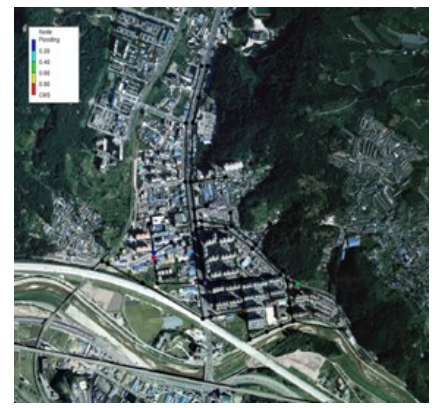

(c) The Manholes with Overflow

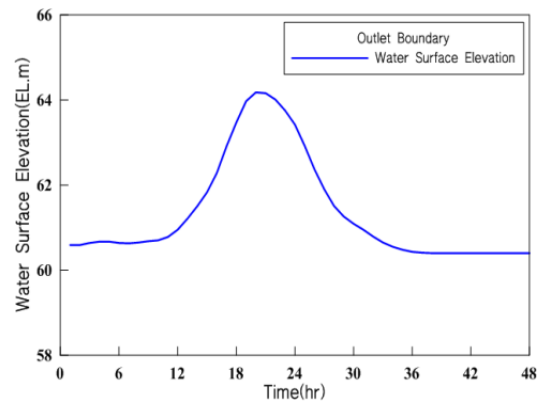

(b) Outlet Boundary

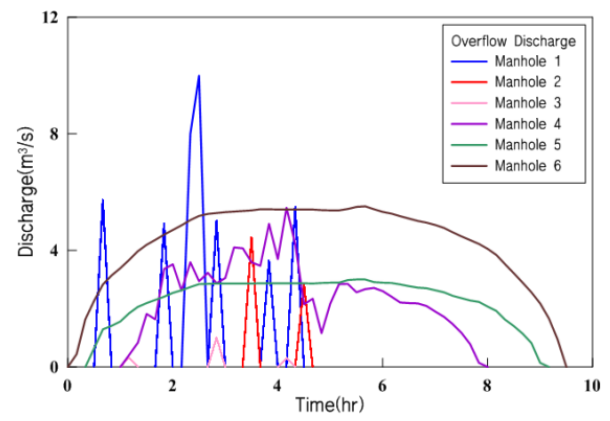

(d) Overflow Discharge Hydrograph

Fig.1. Input Data and Manhole Overflow 


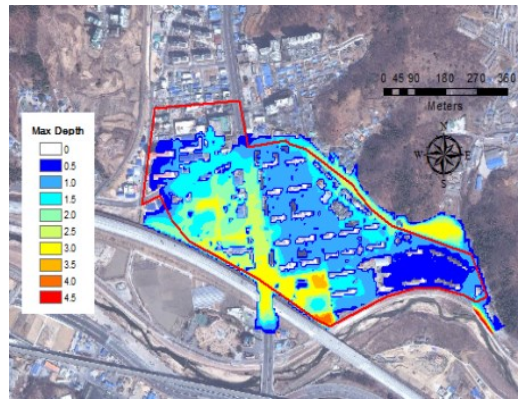

Table 1. Result of Goodness of Fit

\begin{tabular}{|c|c|}
\hline Area & Result \\
\hline Real Inundation Area $\left(\mathrm{m}^{2}\right)$ & 277,739 \\
\hline $\begin{array}{c}\text { Estimate Inundation } \\
\text { Area }\left(\mathrm{m}^{2}\right)\end{array}$ & 228,456 \\
\hline Goodness of Fit(\%) & 81.1 \\
\hline
\end{tabular}

Fig.2. Comparison of Flooded Area

\section{Flood Risk Map for Emergency Management}

\subsection{Flood Hazard Index}

The flood hazard map can be prepared by predicting the expected flooded area, flood depth and velocity. The map can be used as basic data for establishing disaster prevention measure, however, it has some limitations for specific planning such as evacuation route/time and recovery activities. The risk factors of maximum flooding depth and maximum flooding rate are estimated. Fig. 3 represents the degree of flood hazard multiplied by the maximum flooding depth and the maximum flow velocity.

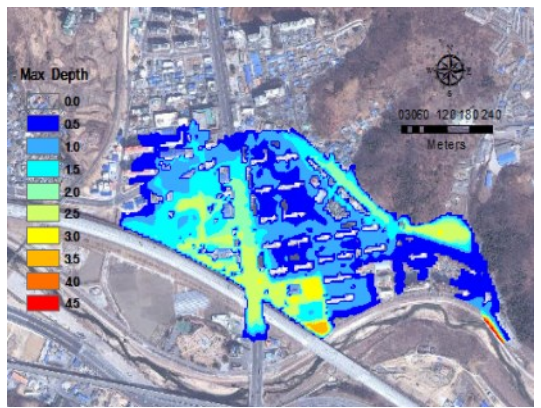

(a) Max Depth

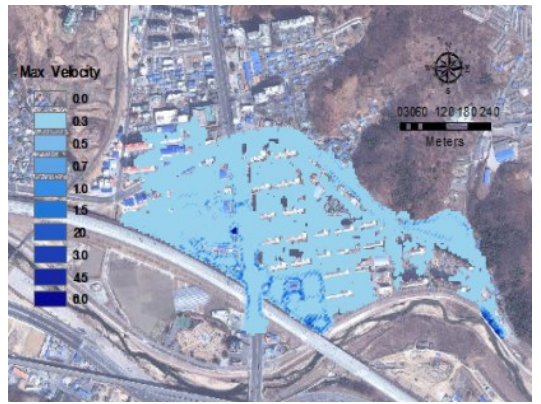

(b) Max Velocity

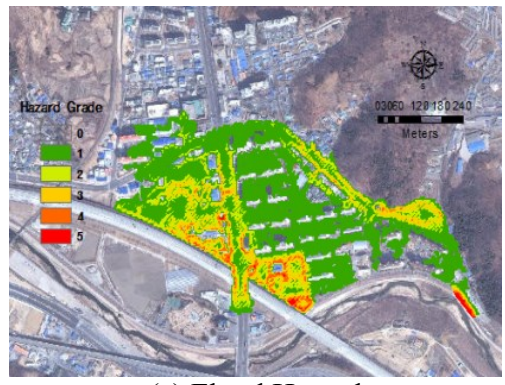

(c) Flood Hazard

Fig 3. Flood Hazard Map 


\subsection{Flood Vulnerability Index}

For the estimation of the flood fragility, the human and sociological factors are considered including population density, household income, shelter site and evacuation route/time. Fig. 4 shows the indicators used for the vulnerability analysis, and the data extracted for each index are ranked from 1 to 5 .

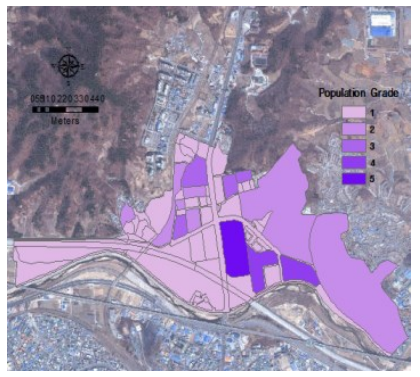

(a) Population Density

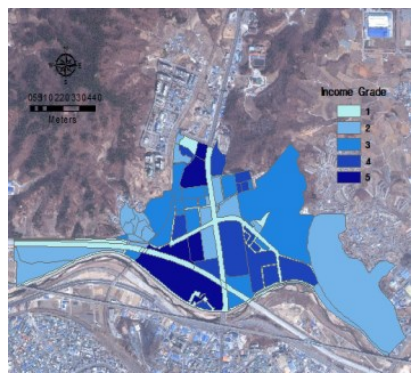

(b) Income

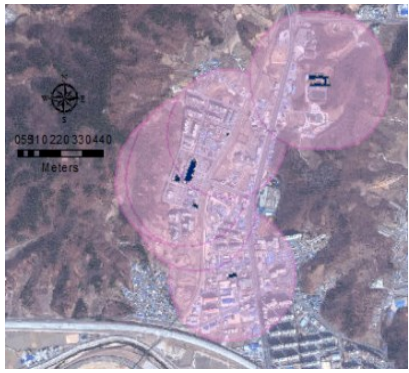

(c) Evacuation (Adult, 5min)

Fig 4. Flood Vulnerability Map

\subsection{Flood Risk Mapping}

To minimize the damage in the event of a disaster, and to move people to the designated evacuation site safely, it is important to exercise evacuation activities along with specific disaster guidance. In addition, evacuation planning will vary depending on the situation such as population, assets, and buildings in each region. In this paper, a risk map which is useful for evacuation planning is prepared by superimposing indicators derived from flood forecasting and vulnerability analysis.

Fig. 5 shows the various types of the risk map with population density, household income, evacuation route/time by overlaying the flood hazard. The shelter site, which will be important for selecting the evacuation time/route, selected actual location used at typhoon Rusa on 2002. The access time to the shelter site considered as the range from 5 to 30 minutes by adult walk. The concentric cirlcles are drawn at major shelter sites for travel time from any place from those sites.

It will be possible to evacuate to the shelter site according to the number of residents in the flooded area along with available time and route. The vulnerability indicators presented can be used to establish safe and accurate evacuation plans by overlapping the flood hazard including risk. 


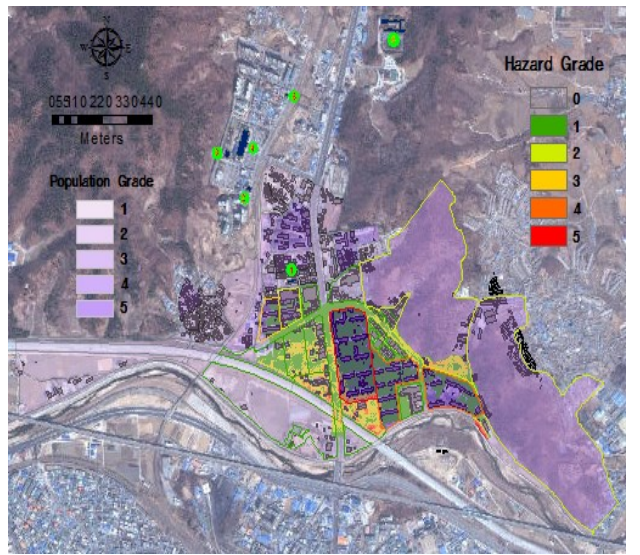

(a) Hazard with Population

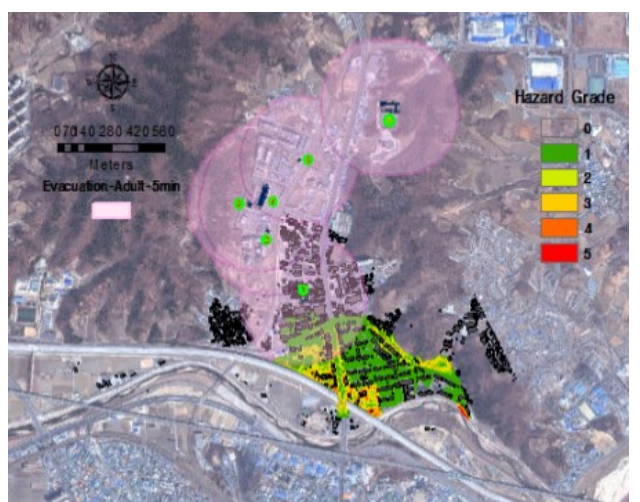

(c) Hazard with Evacuation Time (5 min)

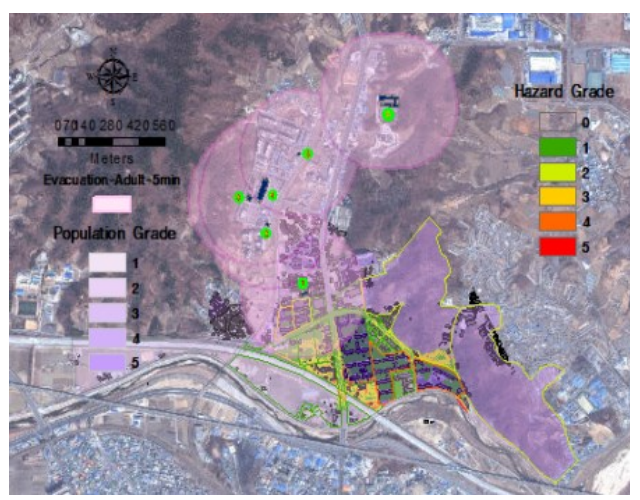

(e) Hazard with Population and Evacuation (5 min)

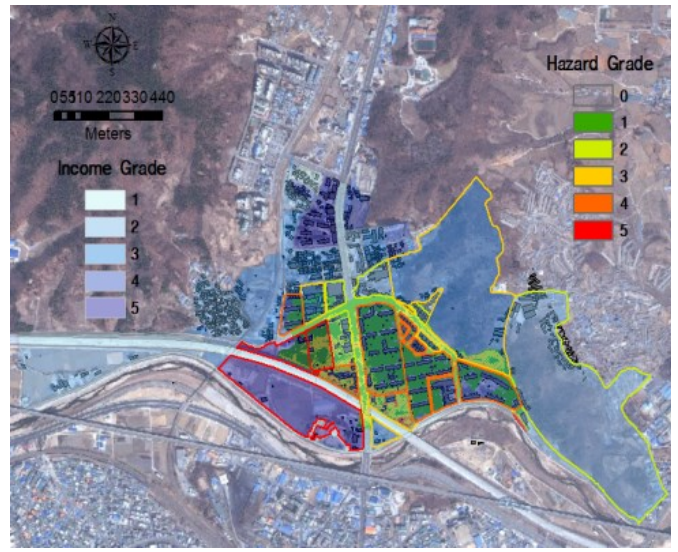

(b) Hazard with Household Income

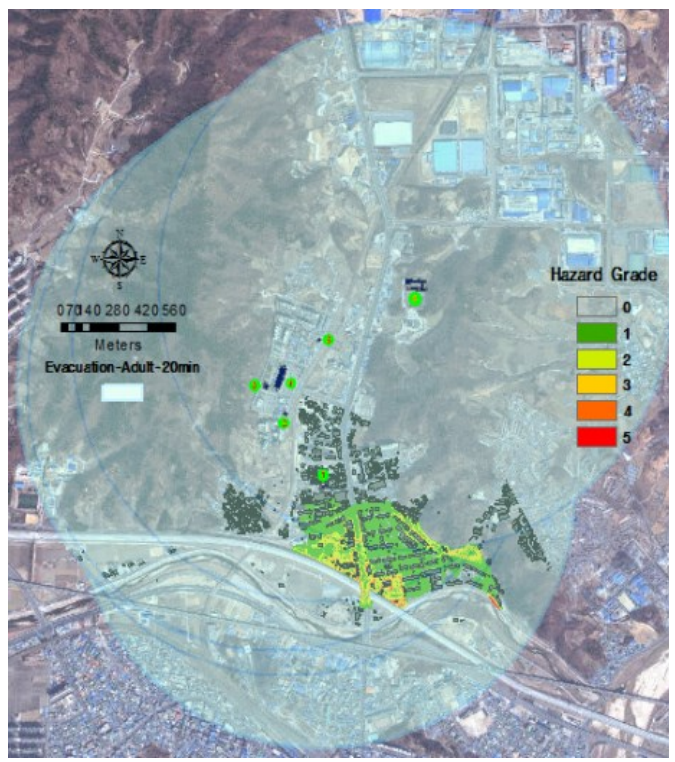

(d) Hazard with Evacuation Time(20 min)

Fig. 5. Flood Risk Map

\section{Conclusions}

A grid-based 2D model is developed to create a new disaster map, which provide more useful information of disaster areas is proposed. 
1. A two-dimensional inundation analysis model is developed to reflect accurate input data such as LiDAR and to obtain accurate inundation analysis results in a short time.

2. Verification of the actual flood event shows the accuracy of the developed model. The model can reflect the topographic data such as buildings and roads and perform the fast simulation with good accuracy.

3. A new disaster map is presented by superimposing the vulnerability index derived from the flood hazard. Based on the population density, estimated income quintiles, and evacuation time/route, the risk map can provide various types of information in evacuation and recovery planning, which can contribute to mitigating the urban flood disaster.

\section{Acknowledgement}

This work was supported by the National Research Foundation of Korea(NRF) grant funded by the Korea Government(MSIP) (No. 2017M2A8A4015290).

\section{References}

1. Yu, D. and Lane, S. N., "Urban fluvial flood modeling using a two-dimensional diffusion-wave treatment, part 1: mesh resolution effects." J. of Hydrological Processes, Vol. 20, pp. 1541-1565 (2006).

2. Horritt, M .S. and Bates, P. D., "Predicting floodplain inundation: raster based modeling versus the finite-element approach." J. of Hydrological Processes, Vol. 15, pp. 825-842 (2001).

3. Park, J. H., "Development of disaster mapping methodology by combining grid-based model with integrated risk analysis" Ph.D. Dissertation, Kyungpook National Univeristy, Daegu, Korea, pp. 1-174 (2017). 